\title{
Gamma Oscillation in Schizophrenia
}

\author{
Yong-Wook Shin ${ }^{\bowtie}$, Brian F. O’Donnell ${ }^{2}$, Soyoung Youn ${ }^{1}$ and Jun Soo Kwon ${ }^{3}$ \\ ${ }^{1}$ Department of Psychiatry, ASAN Medical Center, University of Ulsan College of Medicine, Seoul, Korea \\ 2Department of Psychological and Brain Sciences, Indiana University, Bloomington, IN, USA \\ ${ }^{3}$ Department of Psychiatry, Seoul National University School of Medicine, Seoul, Korea
}

Dysfunctional neural circuitry has been found to be involved in abnormalities of perception and cognition in patients with schizophrenia. Gamma oscillations are essential for integrating information within neural circuits and have therefore been associated with many perceptual and cognitive processes in healthy human subjects and animals. This review presents an overview of the neural basis of gamma oscillations and the abnormalities in the GABAergic interneuronal system thought to be responsible for gamma-range deficits in schizophrenia. We also review studies of gamma activity in sensory and cognitive processes, including auditory steady state response, attention, object representation, and working memory, in animals, healthy humans and patients with schizophrenia.

Psychiatry Investig 2011;8:288-296

Key Words Gamma oscillations, Schizophrenia, GABAergic interneurons, Steady state response.

\section{INTRODUCTION}

Individuals with schizophrenia show diverse symptoms and deficits in multiple domains of perception and cognition. ${ }^{1-3}$ These include cognitive disturbances, such as attention deficits and delusional ideation; disturbances of self-awareness and agency; alterations in emotional expression; disturbed motor behavior; and sensations in the absence of external stimulation, or hallucinations. These varied abnormalities in schizophrenia may be due to a dysfunction in neural circuitry, which affects many brain systems, rather than to a lesion affecting a localized site. One model that has garnered much attention in the past decade is the "disconnection hypothesis," which proposes that schizophrenia disrupts signaling among brain regions, systems or cellular circuits. ${ }^{4,5}$ As early as a century ago, Wernicke hypothesized that psychosis was caused by a pathology of association fibers. ${ }^{6}$ Recently, diffusion tensor imaging has suggested that changes occur in the integrity of the white matter tract in schizophrenia, ${ }^{7}$ findings are supported by

Received: July 21, 2011 Revised: September 8, 2011

Accepted: September 19, 2011 Available online: December 8, 2011

$\triangle$ Correspondence: Yong-Wook Shin, MD, PhD

Department of Psychiatry, Ulsan University School of Medicine, 86 Asanbyeongwon-gil, Songpa-gu, Seoul 138-736, Korea

Tel: +82-2-3010-3413, Fax: +82-2-485-8381, E-mail: shaman@amc.seoul.kr

(c) This is an Open Access article distributed under the terms of the Creative Commons Attribution Non-Commercial License (http://creativecommons.org/licenses/by$\mathrm{nc} / 3.0$ ) which permits unrestricted non-commercial use, distribution, and reproduction in any medium, provided the original work is properly cited. post-mortem analysis of white matter pathology. ${ }^{8,9}$ Deficits in functional connectivity have been consistently observed in schizophrenia, as shown by reduced interregional correlations of positron emission tomography and functional magnetic resonance imaging signals. Functional connectivity has been reported to affect the prefrontal, temporal, cingulate and parietal cortices in individuals with schizophrenia. ${ }^{10-12}$

Functional dysconnectivity may result from structural alterations in axonal integrity, differences in mapping of projections among brain regions or physiological disturbances of neurotransmission. Disruption of neural synchrony and oscillations, for example, could have a marked impact on functional connectivity within and across brain regions. Findings from cellular, local field potential, and electroencephalographic recordings suggest that gamma oscillations $(>30 \mathrm{~Hz})$ are important for integration of information within neural circuits. Gamma oscillations in the neural system were first reported in the olfactory nerves of hedgehogs, which in response to olfactory stimulation, produced trains of sinusoidal oscillations in the gamma frequency band. ${ }^{13}$ More recently, gamma oscillations have been associated with numerous perceptual and cognitive processes, including attention, ${ }^{14-17}$ memory, ${ }^{18,19}$ object recognition, ${ }^{20}$ word processing, ${ }^{21,22}$ and consciousness. ${ }^{23}$

Electroencephalography (EEG) and magnetoencephalography (MEG) have shown that schizophrenia is characterized by alterations in synchrony and oscillatory activity in a variety of paradigms, particularly in the gamma range. These disturb- 
ances could have pervasive effects on cognitive function. This review will provide an overview of the neural basis of gamma range oscillations, methods of eliciting and measuring gamma activity in humans and animals, evidence for the roles of gamma activity in sensory and cognitive processes, and findings in schizophrenia.

\section{CELLULAR MECHANISMS SUPPORTING GAMMA OSCILLATIONS}

Gamma oscillations have been observed in many cortical regions and networks, including visual, ${ }^{24,25}$ auditory, ${ }^{26}$ motor, ${ }^{27}$ parietal, ${ }^{19}$ and hippocampus. ${ }^{28,29}$ Due to its simple laminar structure, which generates higher gamma power than other cortical areas, the hippocampus has been most frequently used in investigations of the cellular mechanisms underlying the generation of gamma oscillation. ${ }^{30}$ The first in vitro demonstration that networks of inhibitory gamma-aminobutyric acid (GABA) interneurons generated gamma oscillations were in rat hippocampal specimens. ${ }^{31}$ Tetanic stimulation evoked gamma oscillation in the CA1 region, even in the presence of glutamate receptor inhibitors, suggesting that excitatory neuronal function might not be necessary for gamma oscillations. ${ }^{31}$ In contrast, gamma oscillations were totally blocked by the GABA type A receptor antagonist bicuculline, suggesting that GABAergic interneurons are essential in generating gamma oscillations. ${ }^{31}$ Moreover, single GABAergic interneurons were observed to synchronize the firing of a large number of pyramidal cells, due to the divergence of outputs from these GABAergic interneurons. ${ }^{32}$

GABAergic interneurons are present throughout the cerebral cortex, extending to all layers and constituting approximately about $25-30 \%$ of the neuronal population in primate neocortices. ${ }^{33,34}$ These interneurons can be categorized according to their electrophysiological characteristics, as fast-and non-fast-spiking interneurons; according to their formation of synapses with other neurons, as soma-inhibiting and dendriteinhibiting; or immunocytochemically, according to their localized expression of calcium-binding proteins, such as parvalbumin, calretinin, and calbindin..$^{35}$ Among those subpopulations, GABAergic neurons that express parvalbumin were found to generate gamma oscillations in vivo and in vitro. ${ }^{36,37}$ Stimulation of parvalbumin GABAergic interneurons was found to increase gamma oscillations, whereas inhibition of these interneurons suppressed gamma oscillations. ${ }^{37}$ However, even if GABAergic interneurons are primarily responsible for gamma oscillations, pyramidal neurons, the principal class of excitatory neurons, are required to induce long-range gamma synchronization in networks that exceed the limited spatial projections of GABA neurons. Pyramidal neurons show- ing intrinsic generation of $20-$ to $70-\mathrm{Hz}$ repetitive firing, or chattering cells, ${ }^{38}$ were found to constitute $10-15 \%$ of intracellularly-recorded neurons, with each chattering cell diverging into a large population of cortical neurons. The repetitive firing by chattering cells was not spontaneous but was induced by suprathreshold depolarizing current injection, ${ }^{38}$ suggesting that gamma oscillations could be elicited by afferent stimulation of these cells in vivo.

The negative feedback interaction between pyramidal cells and fast-spiking interneurons could also generate gamma oscillations. For example, a characteristic phase relationship during gamma oscillation was observed between pyramidal cells and interneurons in the rodent hippocampus, such that interneurons fired a few milliseconds after pyramidal cells. ${ }^{28}$ Excitatory input from pyramidal cell firing likely induces inhibitory interneurons to generate synchronized activity, thus imposing gamma oscillation onto the entire local network. However, the combined action of pyramidal cells and GABAergic interneurons does not suffice to explain long-range gamma synchronization. Most gamma oscillations occurred with zerophase lag, indicating modulation of neuronal activity without any temporal delay between areas. This is intriguing, since many factors, such as conduction time and synaptic delay, contribute to delays in propagation of neural signals in cortical networks. Electrical gap junctions may be relevant to rapid oscillatory induction. Electrical gap junctions have been observed between interneurons and between pyramidal cells and interneurons, and blockade of gap junctions has been reported to reduce gamma oscillation (Figure 1$).{ }^{39}$

\section{CELLULAR MECHANISMS FOR GAMMA-RANGE DEFICITS IN SCHIZOPHRENIA}

Combined networks of pyramidal neurons and GABAergic interneurons are most likely the neural substrates that generate gamma oscillation. Abnormalities in both systems have been reported in patients with schizophrenia. For example, a post-mortem study reported that the volume of pyramidal neurons ${ }^{40}$ and the densities of axon terminal markers in the auditory cortex ${ }^{41}$ were lower in patients with schizophrenia than in normal controls. Patients with schizophrenia also showed deficits in glutamatergic synaptic connectivity in pyramidal cells. ${ }^{42}$ Phencyclidine an antagonist of the N-methyl-D-aspartate (NMDA) subtype of glutamate receptor, has been shown to induce schizophrenia-like symptoms, including paranoid ideation, depersonalization and hallucinations, via hypofunctioning of NMDA receptors in pyramidal cells. ${ }^{43-45}$

Deficits in GABAergic interneurons have been found consistently in schizophrenia. A postmortem study found that the 


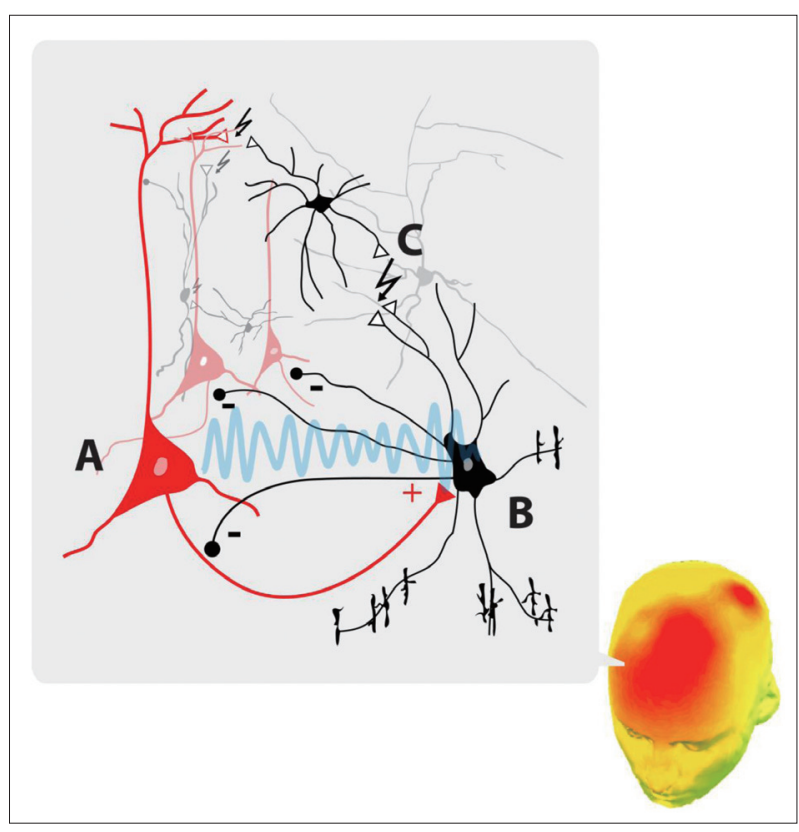

Figure 1. Schematic representation of the GABAergic interneurons and pyramidal neurons that generate gamma oscillation. A) Pyramidal neurons send excitatory signals to $B$ ) chandelier cells, a type of fast-spiking, parvalbumin-producing GABAergic interneuron, which in turn sends inhibitory signals back to the pyramidal cells. Activated interneurons can propagate inhibitory signals to multiple pyramidal cells and other electrically coupled $\left(C_{z}\right)$ interneurons via $\mathrm{C}$ ) electrical gap junctions. The excitatory input from pyramidal cells and the inhibitory responses of the GABAergic interneurons generate synchronized activity imposing gamma oscillation onto the entire local network.

level of mRNA encoding the $67 \mathrm{kD}$ isoform of glutamic acid decarboxylase (GAD), the key enzyme in GABA synthesis, was lower in the dorsolateral prefrontal cortex ${ }^{46}$ and the anterior cingulate cortex ${ }^{47}$ of patients with schizophrenia than in normal controls. Moreover, the level of mRNA encoding the neuronal GABA transporter-1 (GAT-1) protein in the prefrontal cortex ${ }^{48}$ and the density of GABA immunoreactive transporter axons termed "cartridges", which synapses exclusively at the axon initial segment of pyramidal cells in the dorsal prefrontal cortex ${ }^{49}$ were lower in patients with schizophrenia than in controls. The GABAergic deficits in schizophrenia were mostly in the basket and chandelier types of interneurons, ${ }^{50}$ both of which have fast-spiking and parvalbuminproducing properties, ${ }^{43}$ which seem crucial for generating gamma oscillation. ${ }^{5,51}$ A study of mRNA transcripts encoding GABA-related substances in multiple cortical areas of patients with schizophrenia showed that levels of mRNA encoding somatostatin, parvalbumin, GAD, GABA A receptor, and GAT-1 were lower in patients with schizophrenia, with one of the greatest decreases observed for parvalbumin mRNA. ${ }^{52}$

Alterations in glutamatergic neurotransmission may lead to changes in the GABAergic system. In animals, treatment with an NMDA receptor antagonist induced reductions in GAD and parvalbumin mRNAs in GABAergic interneurons. ${ }^{53,54} \mathrm{NM}$ DA hypofunction may lead to failure of exciting parvalbumin-producing GABA interneurons since these interneurons monitor NMDA receptor activity; thus hypofunctioning of NMDA may be falsely interpreted as inactivity of the pyramidal cell system, resulting in low production of GAD or GABA in the inhibitory interneuronal system. ${ }^{43}$ This hypothesis, that NMDA hypofunction is responsible for schizophrenia, also suggests deficits of gamma oscillation in individuals with schizophrenia.

\section{GAMMA OSCILLATIONS IN SENSORY AND COGNITIVE FUNCTION}

\section{Sensory processing in healthy subjects and animals: Auditory steady state response}

Auditory and visual stimuli at specific frequencies entrain EEG activity, called a steady state response (SSR), an evoked EEG potential whose frequency components remain constant in amplitude and phase during sensory processing of presented stimuli. ${ }^{55}$ In healthy subjects, amplitude modulated tones or click sounds evoked auditory SSR (ASSR), with stimuli of about $40 \mathrm{~Hz}$ inducing maximal spectral power. ${ }^{56}$ Although superposition of mid-latency event related potentials (ERPs) may generate these $40 \mathrm{~Hz}$ ASSRs, ${ }^{57,58}$ gamma range ASSRs reflect the phase reorganization of neuronal responses with their intrinsic resonance frequency, rather than the superposition of mid-latency ERPs. ${ }^{59}$ This superposition hypothesis could not explain the shortened phase delay of ASSR after repeated stimuli or continued phase synchronization after offset of a stimulus. ${ }^{60,61}$

Studies in animals have shown that the auditory cortex and the subcortical structure, including the hippocampus and inferior colliculus, play key roles in the generation of ASSRs. ${ }^{62-64}$ In cats, lesions in the lower auditory structures, including the inferior colliculus, were reported to decrease the phase synchrony of the ASSR in the gamma range. ${ }^{62}$ Ablation of the auditory cortices and inferior colliculi was reported to decrease ASSR to $40 \mathrm{~Hz}$ trains of clicks. ${ }^{64}$ Rats with neonatal ventral hippocampal lesions failed to show increased intensity and synchronization of ASSR after injection of GABA A receptor agonist, findings observed in control rats. ${ }^{65}$

\section{Sensory processing in schizophrenia: ASSR}

Deficits in ASSR have been reported in patients with schizophrenia. ${ }^{60}$ The spectral power on frontal EEG channels evoked by $40 \mathrm{~Hz}$ clinic trains was lower, whereas the phase delay, defined as the time gap between a click and the EEG peak response while listening, was higher in patients with schizophrenia than in control subjects. ${ }^{60}$ The decreased phase delay 
after stimulus offset observed in patients with schizophrenia compared with control subjects suggested that the neuronal assembly in patients with schizophrenia had deficits in the synchronization and/or desynchronization to presented stimuli. ${ }^{60}$ In addition, patients with schizophrenia showed reductions in evoked power and phase synchronization to steady state auditory stimulation in the gamma range. ${ }^{66}$ Moreover, relatives of patients with schizophrenia who had schizophrenic spectrum personality symptoms showed reduced gamma power on the frontal channels to steady state auditory stimulation at $40 \mathrm{~Hz}$, although gamma power was not lower in patients with schizophrenia than in control subjects. ${ }^{67}$ In contrast, patients with schizophrenia taking atypical antipsychotics showed enhanced gamma power at $40 \mathrm{~Hz}$ stimulation compared with patients taking conventional antipsychotics. ${ }^{67}$

\section{Sensory integration and object representation in healthy subjects and animals}

Following the first report of gamma oscillations in hedgehog brains, ${ }^{13}$ gamma oscillations in human brains were first reported in intracranial recordings of patients with epilepsy while the patients performed simple visual tasks. ${ }^{68}$ However, the significance of gamma oscillations was not known until they were shown to play a role in integrating sensory information. ${ }^{24,69,70}$ Local field potential (LFP) and multiunit activity (MUA) were measured in the primary visual cortices of cats responding to visual stimuli. ${ }^{24} \mathrm{LFP}$ measures the synchronized neural activity of local populations of neurons, whereas MUA measures spikes of several neurons. Therefore, simultaneous recording of LFP and MUA can reveal the relationship between cortical oscillations and individual neuronal activity. Individual neuronal firings, as measured by MUA, were found to be synchronized to the rhythm of gamma oscillations of LFP if the neurons were coding common primary visual properties of a visual stimulus, even if the neurons were spatially discrete. ${ }^{24}$ Similarly, recording the neuronal activity in two areas of cat visual cortices, the posteromedial lateral suprasylvian area and area 17, which function in global pattern and fine grain analyses of visual objects, respectively, showed that the two groups of neurons fired synchronously on gamma oscillation in response to coherently moving lines, but not to two lines moving in opposite directions. ${ }^{70}$ These findings suggested that two separate groups of neurons integrated information across different feature domains through temporal synchronization on gamma oscillation.

Increased gamma oscillations were observed in patients requiring sensory integration, from simple perceptions like seeing a moving bar to higher cognitive processes including object representation. The perception of illusory objects induced gamma oscillations in human brains. The spectral power of gamma oscillations in the occipital area of scalp EEG was found to be higher for coherently downward moving lines than for irregularly moving lines. ${ }^{71}$ Healthy subjects watching coherent but not incoherent dot motion showed increased gamma activity around $40 \mathrm{~Hz}$ (Figure 2). ${ }^{72}$

Perceiving the Kanizsa triangle also induced gamma oscillations, whereas non-triangle control stimuli did not. ${ }^{73,74} \mathrm{Simi}-$ larly, illusory triangles increased spectral activity at the $70 \mathrm{~Hz}$ MEG frequency band compared with no triangles and increased activity at $90 \mathrm{~Hz}$ compared with real triangles. ${ }^{75}$ Recognition of illusory triangles requires the identification of all elements comprising the triangle and their linkage globally across space. ${ }^{76}$ Therefore, the emergence of gamma oscillations following the recognition of illusory objects suggests that gamma oscillations play a key role in binding information for object representation in the brain.

\section{Sensory integration and object representation in schizophrenia}

In time frequency analysis of ERP, the phase-locking factor (PLF) measures the consistency of the phases of EEG responses across trials of presented stimuli at each frequency. PLF that measures the synchronization of a neuronal assembly to a stimulus may be a better biomarker than measures of EEG power for patients with schizophrenia spectrum disorders. ${ }^{77}$ Patients with schizophrenia showed deficits in PLF while perceiving both illusory and non-illusory stimuli, with deficits more prominent for illusory than non-illusory stimuli. ${ }^{78}$ As the PLF gap between illusory and non-illusory stimuli became larger in control subjects, so did the ability to recognize illusory stimuli, as measured by the difference in reaction time (RT) between illusory and non-illusory stimuli. In patients with schizophrenia, however, there was no such relationship between PLF and performance. ${ }^{78}$ Although gamma synchronization during recognition of Mooney faces was lower in patients with schizophrenia than in control subjects, the gamma power was not decreased during Mooney face recognition in patients with schizophrenia. ${ }^{79}$

\section{Working memory and attention in healthy subjects and animals}

Scalp EEGs showed that gamma activities were increased in subjects asked to find a hidden dog figure in a picture with scattered black blobs, while keeping the dog figure in mind. ${ }^{80} \mathrm{In}$ creases in gamma activity were observed when subjects were asked to match a previously presented figure, but not in the control task requiring no memorization. ${ }^{18}$ The involvement of gamma oscillation in memory tasks was also reported in macaque monkeys, with elevated coherence in gamma frequency between a single neuronal activity and LFP in the lateral intra- 


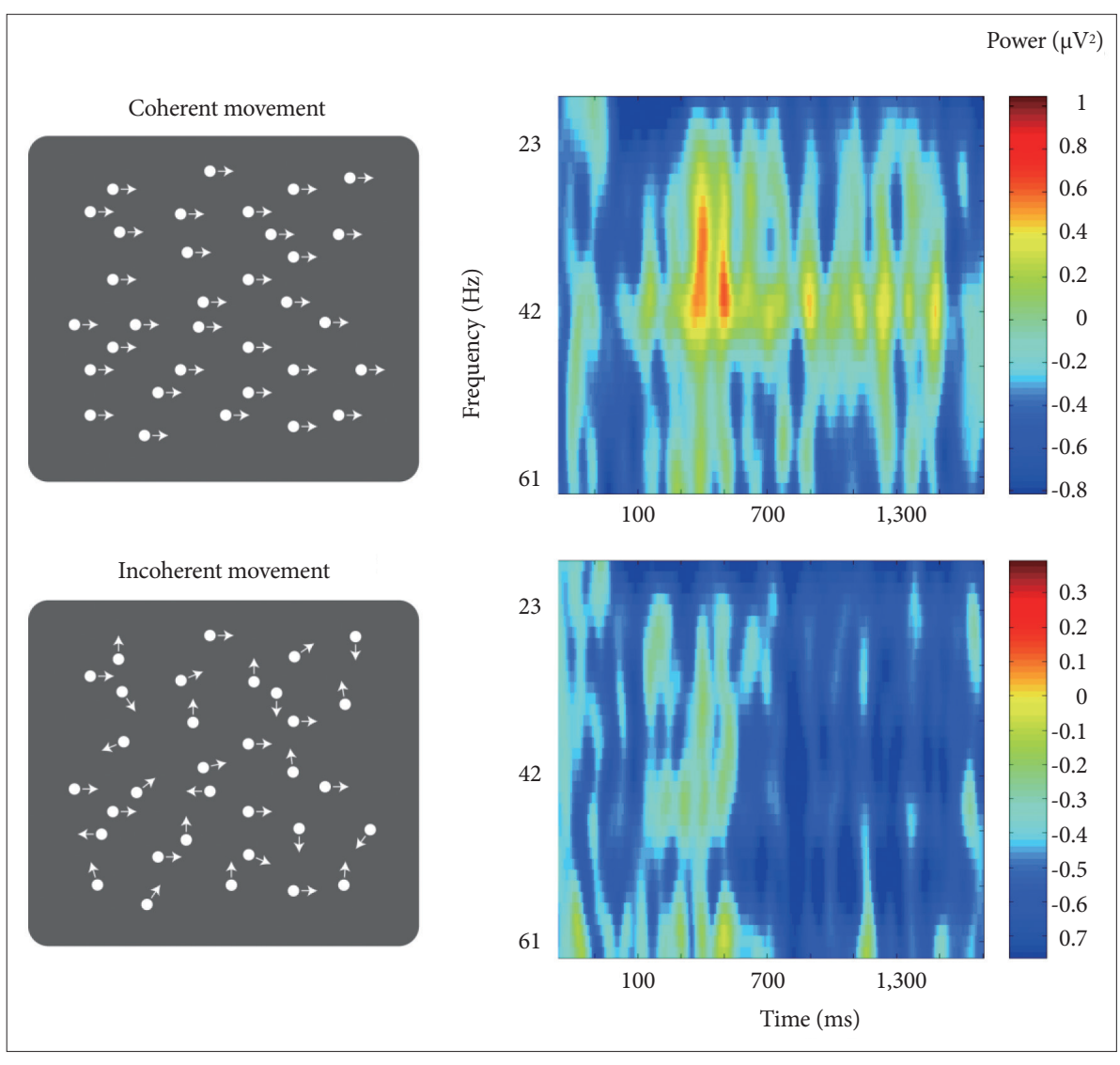

Figure 2. Increase in gamma activity during the perception of coherent and incoherent dot motions by healthy subjects. The left column shows the two stimulus conditions, for coherently displaced dots from left to right (upper) and for incoherently displaced dots at randomly generated angles (lower). The right column shows time-frequency spectrograms of averaged electroencephalography power for coherent (upper) and incoherent (lower) dot motions in the channel Pz (Figure courtesy of Giri P. Krishnan). parietal area of the brain during the memory period. ${ }^{19}$

Attention increased gamma oscillations in the brains of animals and human subjects. When macaque monkeys attended to visual stimuli, their activated neurons showed increased gamma oscillation, ${ }^{15}$ with selective attention to visual stimuli increased gamma oscillation of LFP in area V4. ${ }^{14}$ In monkeys trained to respond to a stimulus, the RT was decreased if the degree of synchronization was increased between gamma oscillation of LFP and individual neuronal firings during the time period before response cues. ${ }^{14}$ Gamma oscillation was also increased by attention in human subjects. Scalp EEG showed that gamma activity was higher for attended stimuli over parieto-occipital areas. ${ }^{81}$ Only consciously perceived stimuli were found to induce long-range gamma phase synchrony, whereas subliminal stimuli increased local gamma oscillation. ${ }^{23}$ However, attention is not mandatory in generating gamma oscillation considering early studies using the visual systems of anesthetized animals to generate gamma oscillations..$^{24,69,70}$

\section{Working memory and attention in schizophrenia}

Patients with schizophrenia showed a deficit in gamma activity in the frontal area during mental arithmetic tasks. ${ }^{82} \mathrm{Gam}$ ma activity during the retrieval period of working memory was reduced in patients with schizophrenia compared with healthy subjects. ${ }^{83}$ Healthy subjects had increased gamma activity in the prefrontal cortex in response to increased demands of executive control in a working memory task, a finding not observed in patients with schizophrenia. ${ }^{84}$ Similarly, healthy subjects, but not patients with schizophrenia, showed increased gamma activity with increased working memory load. ${ }^{85}$ Patients with first onset schizophrenia were recently found to show reduced gamma power in the frontal area during the delay period of a preparatory cognitive task compared with control subjects, regardless of medication status. ${ }^{86}$

The evoked gamma oscillation studies using the auditory oddball task have shown inconsistent results in patients with schizophrenia. Gamma activity, narrowly defined as $37-41 \mathrm{~Hz}$ in response to standard tones of auditory oddball tasks, was lower in medicated patients with schizophrenia than in control subjects. ${ }^{87}$ In addition, gamma activity to target tones was also lower 200-400 ms after a stimulus in patients with schizophrenia than in control subjects. ${ }^{87}$ However, evoked gamma activity to standard tones of the auditory oddball task did not differ between unmedicated patients with schizophrenia and control subjects, whereas gamma activity in response to target tones was lower in patients with schizophrenia than in controls. ${ }^{88}$ Abnormal gamma activity was also observed in the phase coherence between EEG channels in schizophrenia. For 
example, impaired fronto-central gamma coherence was reported in unmedicated patients with schizophrenia, ${ }^{89}$ and decreased evoked gamma power in auditory oddball paradigms was observed in medicated first-episode patients with schizophrenia. ${ }^{90}$ However, evoked gamma activity in the auditory oddball task was reported similar in control subjects and chronic patients with schizophrenia. ${ }^{91}$ A study of a modified auditory oddball task in a large number of patients with schizophrenia found that early-evoked gamma activity was lower in these patients than in a control group. ${ }^{92}$

In contrast to conflicting results on evoked gamma power in schizophrenia, gamma phase locking was consistently reported to be lower in schizophrenia during visual ${ }^{91}$ and auditory oddball tasks. ${ }^{66,93}$ In a study using ASSR to evaluate PLF over a broad range of stimulus frequencies, control subjects showed pronounced increases in PLF and power around the gamma frequency range of stimuli, whereas patients with schizophrenia showed deficits in both PLF and mean power in broadband frequencies, including gamma frequency. A noise embedded in the $40 \mathrm{~Hz}$ stimulus decreased PLF only in control subjects, whereas patients with schizophrenia showed diminished overall PLF.9 ${ }^{94}$

\section{GAMMA OSCILLATION AND SYMPTOMS OF SCHIZOPHRENIA}

Interestingly, symptoms of schizophrenia have been reported to correlate with increased synchronization of gamma oscillation, although mean gamma synchronicity was lower in patients with schizophrenia than in control subjects. ${ }^{79,95-97} \mathrm{Ph}$ ase-locking effects in the occipital area, as measured by differences in PLF during the perception of Gestalt stimuli, correlated with scores of positive symptoms. ${ }^{96}$ The phase-locking effects in the parietal area correlated with negative symptoms in patients with schizophrenia. ${ }^{96}$ Increased gamma phase synchrony averaged across all channels during a Gestalt perception task was positively correlated with positive symptoms, such as delusions and hallucination. ${ }^{79}$ Using ASSR, PLF of the $40 \mathrm{~Hz}$ harmonic of the $20 \mathrm{~Hz}$ stimuli was reported to correlate with positive symptoms in the frontocentral areas of patients with schizophrenia. ${ }^{97}$ Increased gamma synchrony may reflect the retrieval of stored experiences due to the role of gamma activity in internal representations. ${ }^{98}$

\section{CONCLUSION}

Gamma oscillation is a universal phenomenon, found throughout all areas of the brain and across species, from simple perception to higher cognitive functions. The dominant frequency of gamma oscillation changes continuously accord- ing to cortical locations from moment to moment. ${ }^{99}$ Different neuronal groups may communicate during the time window of gamma oscillation, ${ }^{100}$ and the precise phase of gamma oscillations may determine whether neuronal activity could be effectively transmitted among cortical areas. ${ }^{101}$ Therefore, gamma oscillation may be a temporal limitation in the functional connectivity of human and animal brains, modulating efficient information processing at macro and micro levels of neural circuits. The inhibitory feedback of GABAergic interneurons combined with activations of pyramidal neurons seems to generate gamma oscillation. Abnormalities of the neuronal system, including pyramidal neurons and GABAergic interneurons, could result in the deteriorated gamma oscillation observed in schizophrenia. Deficits of gamma oscillation and impaired neuronal communication would result in erroneous processes in a variety of both basic and higher cognitive functions, including sensory perception, coherent feature binding, attention, memory and object representation, all of which would lead to the positive and negative symptoms of schizophrenia.

\section{REFERENCES}

1. Hemsley DR. Schizophrenia. A cognitive model and its implications for psychological intervention. Behav Modif 1996;20:139-169.

2. Choi JS, Park JY, Jung MH, Jang JH, Kang DH, Jung WH, et al. Phasespecific brain change of spatial working memory processing in genetic and ultra-high risk groups of schizophrenia. Schizophr Bull. in press.

3. Shin YW, Na MH, Ha TH, Kang DH, Yoo SY, Kwon JS. Dysfunction in configural face processing in patients with schizophrenia. Schizophr Bull 2008;34:538-543.

4. Friston KJ. The disconnection hypothesis. Schizophr Res 1998;30: 115-125.

5. Andreasen NC, O'Leary DS, Cizadlo T, Arndt S, Rezai K, Ponto LL, et al. Schizophrenia and cognitive dysmetria: a positron-emission tomography study of dysfunctional prefrontal-thalamic-cerebellar circuitry. Proc Natl Acad Sci U S A 1996;93:9985-9990.

6. Stephan KE, Baldeweg T, Friston KJ. Synaptic plasticity and dysconnection in schizophrenia. Biol Psychiatry 2006;59:929-939.

7. Zalesky A, Fornito A, Seal ML, Cocchi L, Westin CF, Bullmore ET, et al. Disrupted axonal fiber connectivity in schizophrenia. Biol Psychiatry 2011;69:80-89.

8. Akbarian S, Bunney WE Jr, Potkin SG, Wigal SB, Hagman JO, Sandman CA, et al. Altered distribution of nicotinamide-adenine dinucleotide phosphate-diaphorase cells in frontal lobe of schizophrenics implies disturbances of cortical development. Arch Gen Psychiatry 1993;50:169-177.

9. Yang Y, Fung SJ, Rothwell A, Tianmei S, Weickert CS. Increased interstitial white matter neuron density in the dorsolateral prefrontal cortex of people with schizophrenia. Biol Psychiatry 2011;69:63-70.

10. Boksman K, Theberge J, Williamson P, Drost DJ, Malla A, Densmore $\mathrm{M}$, et al. A 4.0-T fMRI study of brain connectivity during word fluency in first-episode schizophrenia. Schizophr Res 2005;75:247-263.

11. Honey GD, Pomarol-Clotet E, Corlett PR, Honey RA, McKenna PJ, Bullmore ET, et al. Functional dysconnectivity in schizophrenia associated with attentional modulation of motor function. Brain 2005;128: 2597-2611.

12. Kim JJ, Kwon JS, Park HJ, Youn T, Kang DH, Kim MS, et al. Functional disconnection between the prefrontal and parietal cortices during 
working memory processing in schizophrenia: a[15(O)]H2O PET study. Am J Psychiatry 2003;160:919-923.

13. Adrian ED. Olfactory reactions in the brain of the hedgehog. J Physiol 1942;100:459-473.

14. Womelsdorf T, Fries P, Mitra PP, Desimone R. Gamma-band synchronization in visual cortex predicts speed of change detection. Nature 2006;439:733-736.

15. Fries P, Reynolds JH, Rorie AE, Desimone R. Modulation of oscillatory neuronal synchronization by selective visual attention. Science 2001; 291:1560-1563.

16. Verhoeven WM, van Ree JM, Westenberg HG, Krul JM, Brouwer GJ, Thijssen JH, et al. Clinical, biochemical, and hormonal aspects of treatment with Des-tyrl-gamma-endorphin in schizophrenia. Psychiatry Res 1984;11:329-346.

17. Kinoshita Y, Suzuki T, Ikeda M, Kitajima T, Yamanouchi Y, Inada T, et al. No association with the calcineurin A gamma subunit gene (PPP3 CC) haplotype to Japanese schizophrenia. J Neural Transm 2005;112: 1255-1262.

18. Tallon-Baudry C, Bertrand O, Peronnet F, Pernier J. Induced gammaband activity during the delay of a visual short-term memory task in humans. J Neurosci 1998;18:4244-4254.

19. Pesaran B, Pezaris JS, Sahani M, Mitra PP, Andersen RA. Temporal structure in neuronal activity during working memory in macaque parietal cortex. Nat Neurosci 2002;5:805-811.

20. Leicht G, Karch S, Karamatskos E, Giegling I, Moller HJ, Hegerl U, et al. Alterations of the early auditory evoked gamma-band response in firstdegree relatives of patients with schizophrenia: hints to a new intermediate phenotype. J Psychiatr Res 2011;45:699-705.

21. Pulvermuller F. Hebb's concept of cell assemblies and the psychophysiology of word processing. Psychophysiology 1996;33:317-333.

22. Ihara A, Kakigi R. Oscillatory activity in the occipitotemporal area related to the visual perception of letters of a first/second language and pseudoletters. Neuroimage 2006;29:789-796.

23. Melloni L, Molina C, Pena M, Torres D, Singer W, Rodriguez E. Synchronization of neural activity across cortical areas correlates with conscious perception. J Neurosci 2007;27:2858-2865.

24. Eckhorn R, Bauer R, Jordan W, Brosch M, Kruse W, Munk M, et al. Coherent oscillations: a mechanism of feature linking in the visual cortex? Multiple electrode and correlation analyses in the cat. Biol Cybern 1988;60:121-130.

25. Enomoto T, Tse MT, Floresco SB. Reducing prefrontal gamma-aminobutyric acid activity induces cognitive, behavioral, and dopaminergic abnormalities that resemble schizophrenia. Biol Psychiatry 2011;69: 432-441.

26. Bucci P, Mucci A, Merlotti E, Volpe U, Galderisi S. Induced gamma activity and event-related coherence in schizophrenia. Clin EEG Neurosci 2007;38:96-104.

27. Funk AP, Epstein CM. Natural rhythm: evidence for occult $40 \mathrm{~Hz}$ gamma oscillation in resting motor cortex. Neurosci Lett 2004;371: 181-184.

28. Csicsvari J, Jamieson B, Wise KD, Buzsaki G. Mechanisms of gamma oscillations in the hippocampus of the behaving rat. Neuron 2003;37: 311-322.

29. Fell J, Klaver P, Lehnertz K, Grunwald T, Schaller C, Elger CE, et al. Human memory formation is accompanied by rhinal-hippocampal coupling and decoupling. Nat Neurosci 2001;4:1259-1264.

30. Hirai N, Uchida S, Maehara T, Okubo Y, Shimizu H. Enhanced gamma $(30-150 \mathrm{~Hz})$ frequency in the human medial temporal lobe. Neuroscience 1999;90:1149-1155.

31. Whittington MA, Traub RD, Jefferys JG. Synchronized oscillations in interneuron networks driven by metabotropic glutamate receptor activation. Nature 1995;373:612-615.

32. Cobb SR, Buhl EH, Halasy K, Paulsen O, Somogyi P. Synchronization of neuronal activity in hippocampus by individual GABAergic interneurons. Nature 1995;378:75-78.
33. Jones EG. GABAergic neurons and their role in cortical plasticity in primates. Cereb Cortex 1993;3:361-372.

34. Benes FM, Berretta S. GABAergic interneurons: implications for understanding schizophrenia and bipolar disorder. Neuropsychopharmacology 2001;25:1-27.

35. Bartos M, Vida I, Jonas P. Synaptic mechanisms of synchronized gamma oscillations in inhibitory interneuron networks. Nat Rev Neurosci 2007;8:45-56.

36. Kawaguchi Y, Katsumaru H, Kosaka T, Heizmann CW, Hama K. Fast spiking cells in rat hippocampus (CA1 region) contain the calciumbinding protein parvalbumin. Brain Res 1987;416:369-374.

37. Sohal VS, Zhang F, Yizhar O, Deisseroth K. Parvalbumin neurons and gamma rhythms enhance cortical circuit performance. Nature 2009; 459:698-702.

38. Gray CM, McCormick DA. Chattering cells: superficial pyramidal neurons contributing to the generation of synchronous oscillations in the visual cortex. Science 1996;274:109-113.

39. Traub RD, Kopell N, Bibbig A, Buhl EH, LeBeau FE, Whittington MA. Gap junctions between interneuron dendrites can enhance synchrony of gamma oscillations in distributed networks. J Neurosci 2001;21: 9478-9486.

40. Sweet RA, Bergen SE, Sun Z, Sampson AR, Pierri JN, Lewis DA. Pyramidal cell size reduction in schizophrenia: evidence for involvement of auditory feedforward circuits. Biol Psychiatry 2004;55:1128-1137.

41. Sweet RA, Bergen SE, Sun Z, Marcsisin MJ, Sampson AR, Lewis DA. Anatomical evidence of impaired feedforward auditory processing in schizophrenia. Biol Psychiatry 2007;61:854-864.

42. Coyle JT. The GABA-glutamate connection in schizophrenia: which is the proximate cause? Biochem Pharmacol 2004;68:1507-1514.

43. Lisman JE, Coyle JT, Green RW, Javitt DC, Benes FM, Heckers S, et al. Circuit-based framework for understanding neurotransmitter and risk gene interactions in schizophrenia. Trends Neurosci 2008;31: 234-242.

44. Halberstadt AL. The phencyclidine-glutamate model of schizophrenia. Clin Neuropharmacol 1995;18:237-249.

45. Hashimoto K, Fukushima T, Shimizu E, Komatsu N, Watanabe H, Shinoda N, et al. Decreased serum levels of D-serine in patients with schizophrenia: evidence in support of the N-methyl-D-aspartate receptor hypofunction hypothesis of schizophrenia. Arch Gen Psychiatry 2003;60:572-576

46. Akbarian S, Kim JJ, Potkin SG, Hagman JO, Tafazzoli A, Bunney WE Jr, et al. Gene expression for glutamic acid decarboxylase is reduced without loss of neurons in prefrontal cortex of schizophrenics. Arch Gen Psychiatry 1995;52:258-266.

47. Woo TU, Walsh JP, Benes FM. Density of glutamic acid decarboxylase 67 messenger RNA-containing neurons that express the N-methyl-Daspartate receptor subunit NR2A in the anterior cingulate cortex in schizophrenia and bipolar disorder. Arch Gen Psychiatry 2004;61: 649-657.

48. Ohnuma T, Augood SJ, Arai H, McKenna PJ, Emson PC. Measurement of GABAergic parameters in the prefrontal cortex in schizophrenia: focus on GABA content, GABA(A) receptor alpha-1 subunit messenger RNA and human GABA transporter-1 (HGAT-1) messenger RNA expression. Neuroscience 1999;93:441-448.

49. Pierri JN, Chaudry AS, Woo TU, Lewis DA. Alterations in chandelier neuron axon terminals in the prefrontal cortex of schizophrenic subjects. Am J Psychiatry 1999;156:1709-1719.

50. Zhang ZJ, Reynolds GP. A selective decrease in the relative density of parvalbumin-immunoreactive neurons in the hippocampus in schizophrenia. Schizophr Res 2002;55:1-10.

51. Crespo-Facorro B, Paradiso S, Andreasen NC, O'Leary DS, Watkins GL, Boles Ponto LL, et al. Recalling word lists reveals "cognitive dysmetria" in schizophrenia: a positron emission tomography study. Am J Psychiatry 1999;156:386-392.

52. Hashimoto T, Bazmi HH, Mirnics K, Wu Q, Sampson AR, Lewis DA. 
Conserved regional patterns of GABA-related transcript expression in the neocortex of subjects with schizophrenia. Am J Psychiatry 2008; 165:479-489.

53. Keilhoff G, Becker A, Grecksch G, Wolf G, Bernstein HG. Repeated application of ketamine to rats induces changes in the hippocampal expression of parvalbumin, neuronal nitric oxide synthase and cFOS similar to those found in human schizophrenia. Neuroscience 2004; 126:591-598.

54. Cochran SM, Kennedy M, McKerchar CE, Steward LJ, Pratt JA, Morris BJ. Induction of metabolic hypofunction and neurochemical deficits after chronic intermittent exposure to phencyclidine: differential modulation by antipsychotic drugs. Neuropsychopharmacology 2003; 28:265-275.

55. Picton TW, John MS, Dimitrijevic A, Purcell D. Human auditory steady-state responses. Int J Audiol 2003;42:177-219.

56. Galambos R. Tactile and auditory stimuli repeated at high rates (3050 per sec) produce similar event related potentials. Ann N Y Acad Sci 1982;388:722-728.

57. Galambos R, Makeig S. Physiological studies of central masking in man. I: The effects of noise on the $40-\mathrm{Hz}$ steady-state response. J Acoust Soc Am 1992;92:2683-2690.

58. Capilla A, Pazo-Alvarez P, Darriba A, Campo P, Gross J. Steady-state visual evoked potentials can be explained by temporal superposition of transient event-related responses. PLoS One 2011;6:e14543.

59. Ross B, Herdman AT, Pantev C. Stimulus induced desynchronization of human auditory $40-\mathrm{Hz}$ steady-state responses. J Neurophysiol 2005; 94:4082-4093.

60. Kwon JS, O’Donnell BF, Wallenstein GV, Greene RW, Hirayasu Y, Nestor PG, et al. Gamma frequency-range abnormalities to auditory stimulation in schizophrenia. Arch Gen Psychiatry 1999;56:1001-1005.

61. Brenner CA, Krishnan GP, Vohs JL, Ahn WY, Hetrick WP, Morzorati SL, et al. Steady state responses: electrophysiological assessment of sensory function in schizophrenia. Schizophr Bull 2009;35:1065-1077.

62. Kiren T, Aoyagi M, Furuse H, Koike Y. An experimental study on the generator of amplitude-modulation following response. Acta Otolaryngol Suppl 1994;511:28-33.

63. Kuwada S, Anderson JS, Batra R, Fitzpatrick DC, Teissier N, D’Angelo WR. Sources of the scalp-recorded amplitude-modulation following response. J Am Acad Audiol 2002;13:188-204.

64. Tsuzuku T. $40-\mathrm{Hz}$ steady state response in awake cats after bilateral chronic lesions in auditory cortices or inferior colliculi. Auris Nasus Larynx 1993;20:263-274.

65. Vohs JL, Chambers RA, Krishnan GP, O’Donnell BF, Berg S, Morzorati SL. GABAergic modulation of the $40 \mathrm{~Hz}$ auditory steady-state response in a rat model of schizophrenia. Int J Neuropsychopharmacol 2010;13:487-497.

66. Light GA, Hsu JL, Hsieh MH, Meyer-Gomes K, Sprock J, Swerdlow NR, et al. Gamma band oscillations reveal neural network cortical coherence dysfunction in schizophrenia patients. Biol Psychiatry 2006; 60:1231-1240.

67. Hong LE, Summerfelt A, McMahon R, Adami H, Francis G, Elliott A, et al. Evoked gamma band synchronization and the liability for schizophrenia. Schizophr Res 2004;70:293-302.

68. Chatrian GE, Bickford RG, Uihlein A. Depth electrographic study of a fast rhythm evoked from the human calcarine region by steady illumination. Electroencephalogr Clin Neurophysiol 1960;12:167-176.

69. Gray CM, Konig P, Engel AK, Singer W. Oscillatory responses in cat visual cortex exhibit inter-columnar synchronization which reflects global stimulus properties. Nature 1989;338:334-337.

70. Engel AK, Kreiter AK, Konig P, Singer W. Synchronization of oscillatory neuronal responses between striate and extrastriate visual cortical areas of the cat. Proc Natl Acad Sci U S A 1991;88:6048-6052.

71. Lutzenberger W, Pulvermuller F, Elbert T, Birbaumer N. Visual stimulation alters local $40-\mathrm{Hz}$ responses in humans: an EEG-study. Neurosci Lett 1995;183:39-42.
72. Krishnan GP, Skosnik PD, Vohs JL, Busey TA, O’Donnell BF. Relationship between steady-state and induced gamma activity to motion. Neuroreport 2005;16:625-630.

73. Tallon C, Bertrand O, Bouchet P, Pernier J. Gamma-range activity evoked by coherent visual stimuli in humans. Eur J Neurosci 1995;7: 1285-1291.

74. Tallon-Baudry C, Bertrand O, Delpuech C, Pernier J. Stimulus specificity of phase-locked and non-phase-locked $40 \mathrm{~Hz}$ visual responses in human. J Neurosci 1996;16:4240-4249.

75. Kaiser J, Buhler M, Lutzenberger W. Magnetoencephalographic gamma-band responses to illusory triangles in humans. Neuroimage 2004; 23:551-560.

76. Reinhart RM, Mathalon DH, Roach BJ, Ford JM. Relationships between pre-stimulus gamma power and subsequent $\mathrm{P} 300$ and reaction time breakdown in schizophrenia. Int J Psychophysiol 2011;79:16-24.

77. Shin YW, Krishnan G, Hetrick WP, Brenner CA, Shekhar A, Malloy FW, et al. Increased temporal variability of auditory event-related potentials in schizophrenia and Schizotypal Personality Disorder. Schizophr Res 2010;124:110-118.

78. Spencer KM, Nestor PG, Niznikiewicz MA, Salisbury DF, Shenton ME, McCarley RW. Abnormal neural synchrony in schizophrenia. J Neurosci 2003;23:7407-7411.

79. Uhlhaas PJ, Linden DE, Singer W, Haenschel C, Lindner M, Maurer K, et al. Dysfunctional long-range coordination of neural activity during Gestalt perception in schizophrenia. J Neurosci 2006;26:8168-8175.

80. Tallon-Baudry C, Bertrand O, Delpuech C, Permier J. Oscillatory gamma-band $(30-70 \mathrm{~Hz})$ activity induced by a visual search task in humans. J Neurosci 1997;17:722-734.

81. Gruber T, Muller MM, Keil A, Elbert T. Selective visual-spatial attention alters induced gamma band responses in the human EEG. Clin Neurophysiol 1999;110:2074-2085.

82. Kissler J, Muller MM, Fehr T, Rockstroh B, Elbert T. MEG gamma band activity in schizophrenia patients and healthy subjects in a mental arithmetic task and at rest. Clin Neurophysiol 2000;111:2079-2087.

83. Haenschel C, Bittner RA, Waltz J, Haertling F, Wibral M, Singer W, et al. Cortical oscillatory activity is critical for working memory as revealed by deficits in early-onset schizophrenia. J Neurosci 2009;29:9481-9489.

84. Cho RY, Konecky RO, Carter CS. Impairments in frontal cortical gamma synchrony and cognitive control in schizophrenia. Proc Natl Acad Sci U S A 2006;103:19878-19883.

85. Basar-Eroglu C, Brand A, Hildebrandt H, Karolina Kedzior K, Mathes $\mathrm{B}$, Schmiedt C. Working memory related gamma oscillations in schizophrenia patients. Int J Psychophysiol 2007;64:39-45.

86. Minzenberg MJ, Firl AJ, Yoon JH, Gomes GC, Reinking C, Carter CS. Gamma oscillatory power is impaired during cognitive control independent of medication status in first-episode schizophrenia. Neuropsychopharmacology 2010;35:2590-2599.

87. Haig AR, Gordon E, De Pascalis V, Meares RA, Bahramali H, Harris A. Gamma activity in schizophrenia: evidence of impaired network binding? Clin Neurophysiol 2000;111:1461-1468.

88. Gallinat J, Winterer G, Herrmann CS, Senkowski D. Reduced oscillatory gamma-band responses in unmedicated schizophrenic patients indicate impaired frontal network processing. Clin Neurophysiol 2004; 115:1863-1874.

89. Yeragani VK, Cashmere D, Miewald J, Tancer M, Keshavan MS. Decreased coherence in higher frequency ranges (beta and gamma) between central and frontal EEG in patients with schizophrenia: A preliminary report. Psychiatry Res 2006;141:53-60.

90. Symond MP, Harris AW, Gordon E, Williams LM. "Gamma synchrony" in first-episode schizophrenia: a disorder of temporal connectivity? Am J Psychiatry 2005;162:459-465.

91. Spencer KM, Niznikiewicz MA, Shenton ME, McCarley RW. Sensoryevoked gamma oscillations in chronic schizophrenia. Biol Psychiatry 2008;63:744-747.

92. Leicht G, Kirsch V, Giegling I, Karch S, Hantschk I, Moller HJ, et al. 
Reduced early auditory evoked gamma-band response in patients with schizophrenia. Biol Psychiatry 2010;67:224-231.

93. Roach BJ, Mathalon DH. Event-related EEG time-frequency analysis: an overview of measures and an analysis of early gamma band phase locking in schizophrenia. Schizophr Bull 2008;34:907-926.

94. Krishnan GP, Hetrick WP, Brenner CA, Shekhar A, Steffen AN, O'Donnell BF. Steady state and induced auditory gamma deficits in schizophrenia. Neuroimage 2009;47:1711-1719.

95. Lee KH, Williams LM, Haig A, Gordon E. "Gamma (40 Hz) phase synchronicity" and symptom dimensions in schizophrenia. Cogn Neuropsychiatry 2003;8:57-71.

96. Spencer KM, Nestor PG, Perlmutter R, Niznikiewicz MA, Klump MC, Frumin $\mathrm{M}$, et al. Neural synchrony indexes disordered perception and cognition in schizophrenia. Proc Natl Acad Sci U S A 2004;101:
17288-17293.

97. Spencer KM, Salisbury DF, Shenton ME, McCarley RW. Gamma-band auditory steady-state responses are impaired in first episode psychosis. Biol Psychiatry 2008;64:369-375.

98. Uhlhaas PJ, Singer W. Abnormal neural oscillations and synchrony in schizophrenia. Nat Rev Neurosci 2010;11:100-113.

99. Womelsdorf T, Schoffelen JM, Oostenveld R, Singer W, Desimone R, Engel AK, et al. Modulation of neuronal interactions through neuronal synchronization. Science 2007;316: 1609-1612.

100. Fries P. A mechanism for cognitive dynamics: neuronal communication through neuronal coherence. Trends Cogn Sci 2005;9:474-480.

101. Atallah BV, Scanziani M. Instantaneous modulation of gamma oscillation frequency by balancing excitation with inhibition. Neuron 2009; 62:566-577. 